\title{
PEMBERDAYAAN MASYARAKAT DESA CISEWU BERBASIS POTENSI LOKAL DALAM MEWUJUDKAN MASYARAKAT TANGGAP BENCANA
}

\author{
Emi Sukiyah', Aton Patonah', Zufialdi Zakaria², Rina Devnita ${ }^{3}$, Adjat Sudradjat ${ }^{1}$, \\ Edi Tri Haryanto ${ }^{2}$, dan Dwi Purnomo ${ }^{4}$ \\ ${ }^{1}$ Departemen Geologi Sains, Fakultas Teknik Geologi, Universitas Padjadjaran \\ ${ }^{2}$ Departemen Geologi Terapan, Fakultas Teknik Geologi, Universitas Padjadjaran \\ ${ }^{3}$ Departemen Ilmu Tanah dan Sumberdaya Lahan, Universitas Padjadjaran \\ ${ }^{4}$ Departemen Teknologi Industri Pertanian, Universitas Padjadjaran \\ E-mail: emi.sukiyah@unpad.ac.id
}

\begin{abstract}
ABSTRAK. Desa Cisewu berada di Kabupaten Garut bagian selatan. Wilayah ini merupakan bentangalam perbukitan yang tersusun oleh material vulkanik berumur Kuarter. Struktur geologi berupa kekar dan sesar di kawasan tersebut menambah risiko lahan bersifat labil. Oleh karena itu wajar jika kawasan tersebut rawan gerakan tanah. Populasi penduduk berkembang pesat mengingat wilayah ini strategis. Apalagi wilayah Cisewu merupakan penghubung, antara Jawa Barat bagian tengah dan selatan. Sebagian masyarakat Desa Cisewu telah berulang kali mengalami kerugian akibat bencana longsor. Relokasi warga hampir sulit dilakukan, mengingat budaya masyarakat setempat yang sulit meninggalkan tanah leluhur. Masyarakat Desa Cisewu perlu diberdayakan agar mampu berdikari serta tanggap terhadap darurat bencana gerakan tanah. Pemberdayaan masyarakat dapat dilakukan dengan cara memberikan berbagai pelatihan dan pendampingan dengan metode yang mudah dipahami. Pemahaman wilayah yang labil bisa disisipkan pada berbagai kegiatan dalam rangka pemberdayaan masyarakat. Sosialisasi beragam fenomena alam terkait kebencanaan perlu dilakukan dengan bahasa yang sederhana dan sesuai dengan tingkat pendidikan masyarakat setempat. Di sisi lain, masalah konservasi kawasan rawan bahaya alam juga perlu disosialisasikan. Target masyarakat dapat dikelompokkan berdasarkan usia dan latar belakang pendidikan. Pengembangan usaha berbasis potensi lokal perlu mendapat perhatian khusus. Potensi lokal ini perlu mendapat pendampingan untuk dapat bersaing dengan produk unggulan di daerah lainnya.
\end{abstract}

Kata kunci: Cisewu, pemberdayaan masyarakat, gerakan tanah, potensi lokal, Garut Selatan

\section{THE COMMUNITY EMPOWERMENT OF CISEWU VILLAGE BASED ON LOCAL POTENTIALS IN REALIZING DISASTER RESPONSE COMMUNITIES}

\begin{abstract}
Cisewu area is part of the southern Garut Regency. This region is is included in the hilly landscape which is composed of Quaternary volcanic material. The geological structure that develops in this area is fault and fracture, so that the risk of landslide becomes higher. Therefore, it is one the reason the area is included in hazard area to land movement. The population is growing rapidly considering this region is strategic; connecting lane between central and southern West Java. Some people who lived in Cisewu Village have suffered losses due to landslides almost every year. The Relocation of residents is almost difficult because their culture and behaviour who could not leave their ancestral land. The people of Cisewu Village need to be encouraged to become independent and responsive to geological hazard. Community empowerment can be done by providing various training and mentoring with simple method. Recognizing and understanding of geological hazard can be put in their various activities in the context of community empowerment. Community target are grouped by age and educational background. Local potential-based business development needs special attention and guidance in order to they can compete with superior products in other region.
\end{abstract}

Key words: Cisewu; community empowerment; landslide; local potency; Southern Garut

\section{PENDAHULUAN}

Lokasi pelaksanaan kegiatan Pengabdian Pada Masyarakat (PPM) di Desa Cisewu. Lokasi berjarak sekitar $100 \mathrm{~km}$ dari Bandung. Waktu tempuh tidak dapat diprediksi secara tepat mengingat sebagian jalur jalan berkelok-kelok dan berada pada tebing yang rawan longsor. Akses jalan dapat melalui Bandung - Soreang - Banjaran - Pangalengan - Cisewu dengan waktu tempuh 4 jam atau Bandung - Baleendah - Ciparay - Pacet - Cibeureum - Tarumajaya - Santosa - Pangalengan - Cisewu dengan waktu tempuh 5 jam. Desa Cisewu merupakan ibukota Kecamatan Cisewu Kabupaten Garut Provinsi Jawa Barat. Kantor Kecamatan Cisewu terletak pada koordinat 07²2’39” LS dan 107³0'04” BT (Gambar 1), berada pada bentangalam perbukitan yang tersusun oleh material vulkanik berumur Kuarter. Di beberapa lokasi material mengalami alterasi hidrotermal yang termasuk dalam zona argilik, tanah berupa material lempung yang cenderung labil jika curah hujan tinggi. Struktur geologi berupa kekar dan sesar menambah risiko lahan bersifat labil. Oleh karena itu wajar jika kawasan tersebut rawan gerakan tanah, terutama jika musim penghujan tiba.

Populasi penduduk berkembang pesat, apalagi kawasan Cisewu merupakan penghubung antara wilayah Jawa Barat bagian tengah dengan selatan. Pada umumnya pertambahan penduduk berasal dari pendatang dari wilayah lain, terutama daerah di sekitar Cisewu. Industri penginapan cukup banyak dan merupakan salah satu sumber penghasilan penduduk, di samping bercocok tanam. Relokasi warga hampir mustahil dilakukan mengingat kawasan ini cukup strategis dari aspek 


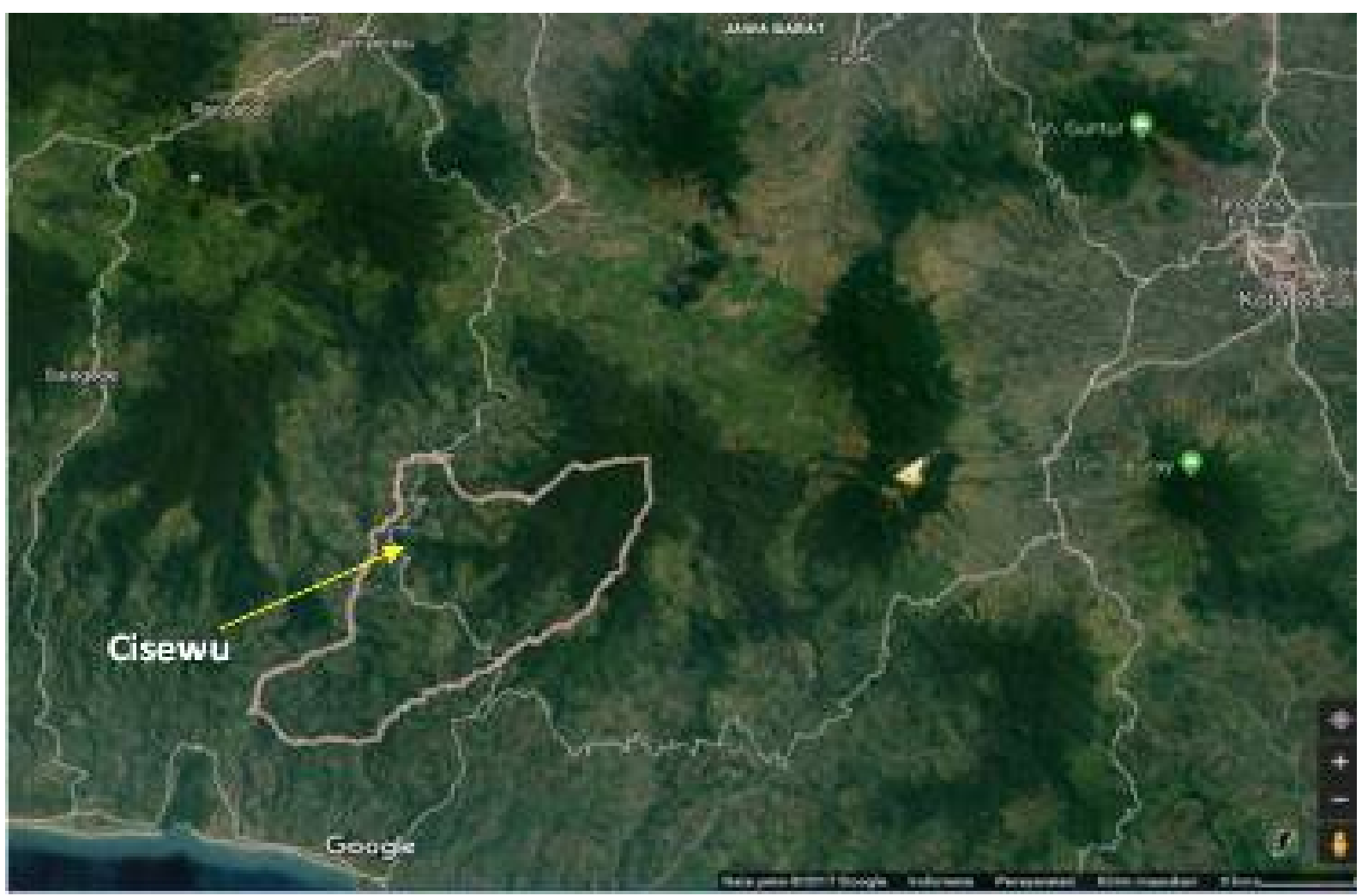

Gambar 1. Lokasi kegiatan PPM di Desa Cisewu, Kecamatan Cisewu, Kabupaten Garut (modifikasi dari Google Map, 2017)

pengembangan ekonomi. Ancaman bencana longsor tidak dianggap penting oleh penduduk setempat. Oleh karena itu, alternatif jalan keluar adalah memberdayakan masyarakat setempat agar tanggap terhadap bencana, diantaranya adalah longsor. Menghindar ketika akan terjadi longsor memerlukan pelatihan rutin. Pemahaman terhadap ciri-ciri akan terjadi longsor perlu ditanamkan sejak dini.

Beberapa permasalahan terkait dengan pemberdayaan masyarakat tanggap bencana longsor, diantaranya adalah:

1. Sebagian besar wilayah Desa Cisewu berupa perbukitan dengan gawir yang rawan longsor. Deteksi dini kejadian longsor dengan metode yang mudah dan murah belum pernah diterapkan di wilayah ini.

2. Masyarakat kesulitan memasarkan hasil bumi dan usahanya karena sering terjadi longsor, memutus jalan penghubung wilayah selatan dan tengah Jawa Barat

3. Masyarakat belum mendapat pembinaan usaha kecil mupun menengah secara berkelanjutan sehingga menghambat perkembangan ekonomi berbasis masyarakat.

Wilayah rawan longsor pada umumnya lahan bersifat labil. Salah penanganan terhadap pengelolaan lahan justru akan berakibat fatal. Banyak pilihan inovasi yang dapat dilakukan. Suwarno dan Andrian (2015) telah melakukan pembinaan terhadap pengembangan masyarakat di Desa Jangalaharja dan Giriharja di wilayah Kabupaten Ciamis, dalam rangka pemanfaatan lahan kritis untuk peternakan ruminansia. Topografi kedua desa berupa perbukitan dengan kondisi jalan hancur sehingga sulit dilalui kendaraan roda empat. Memiliki struktur tanah yang relatif labil sehingga merupakan daerah rawan longsor. Metode yang digunakan adalah demplot partisipatif, yaitu masyarakat dilibatkan dalam pelaksanaan kegiatan sebagai subyek pemberdayaan. Hasil kegiatan tersebut cukup positif, pemahaman masyarakat mengenai lahan kritis dan pemanfaatannya untuk peternakan meningkat.

Fauzielly dkk (2018) menerapkan metode sosialisasi pada anak-anak tingkat Sekolah Dasar di Daerah Hambalang Kabupaten Bogor. Wilayah tersebut rawan bencana longsor. Hasil evaluasi ternyata ada peningkatan pemahaman siswa terkait mitigasi bencana longsor sekitar 22,53\%. Berdasarkan perbandingan hasil uji, dapat disimpulkan bahwa ada peningkatan pengetahuan murid yang diuji setelah kegiatan pembelajaran selesai dilakukan. Diharapkan dengan berhasilnya kegiatan sosialisasi tersebut dapat berkontribusi dalam mengurangi resiko bencana longsor di daerah Hambalang.

Kuswandoro (2016) mengemukakan implementasi Undang Undang Nomor 6 tahun 2014 tentang desa dengan pendekatan Good Village Governance. Pemberlakuan undang-undang tersebut memberikan implikasi pada perubahan drastis dalam pengelolaan unit pemerintahan terkecil di wilayah NKRI. Banyak desa yang belum siap untuk menerapkan undang-undang tersebut. Ketersediaan aparatur pemerintahan di desa sangat terbatas kemampuannya. Hal ini yang menjadi kendala tersendatnya pemberdayaan masyarakat di pedesaan. Peran Perguruan Tinggi yang memiliki sumber daya manusia dengan beragam kompetensi sangat diharapkan oleh masyarakat di pedesaan.

Reulina dkk (2011) melakukan sosialisasi kepada 
anak usia sekolah dasar sebagai upaya membentuk masyarakat tanggap penanggulangan longsor. Masyarakat merupakan subyek yang harus dilibatkan dalam sistem penanggulangan bencana. Kegiatan dilakukan di Desa Bumiwangi Kecamatan Ciparay Kabupaten Bandung. Metode bermain bersama dengan materi simbol-simbol yang terkait dengan mitigasi bencana longsor dikemas secara menarik. Program Kreativitas Mahasiswa ini terpilih untuk PIMNAS XXIV di Universitas Hasanuddin, Makassar.

Pemberdayaan adalah suatu proses individual dan sosial, yakni suatu penguatan kemampuan individual, peningkatan kompetensi, penumbuh kembangan kreativitas (Kuswandoro, 2016). Ketiganya memerlukan kebersamaan yang memperkenankan warga desa mengembangkan perasaan bersama yang menjadi tanggung jawabnya secara mandiri atas dasar kebutuhan. Pemberdayaan masyarakat dapat mencakup:

- Meningkatkan kemampuan dan kemandirian masyarakat dalam meningkatkan taraf hidupnya.

- Menempatkan masyarakat sebagai pihak utama atau pusat pengembangan dengan sasarannya adalah masyarakat yang terpinggirkan.

- Meningkatkan kemampuan masyarakat guna menganalisis kondisi dan potensi serta masalahmasalah yang perlu diatasi, yang intinya adalah melibatkan partisipasi masyarakat dalam proses pemberdayaan masyarakat.

Keterlibatan masyarakat yang diberdayakan sangatlah penting sehingga tujuan dari pemberdayaan dapat tercapai secara maksimal. Program yang mengikut sertakan masyarakat, memiliki beberapa tujuan yaitu agar bantuan tersebut efektif sesuai dengan kehendak dan mengenali kemampuan serta kebutuhan mereka, serta meningkatkan keberdayaan (empowering) masyarakat dengan pengalaman merancang, melaksanakan dan mempertanggungjawabkan upaya peningkatan diri dan ekonomi.

\section{METODE}

Kegiatan pengabdian kepada masyarakat ini dalam rangka menindaklanjuti hasil temuan dalam penelitian sebelumnya, diantaranya keberadaan patahan yang diduga aktif serta material penyusun wilayah yang bersifat labil (Sukiyah dkk, 2015; Sukiyah dkk, 2016; Sukiyah dkk, 2017; Sukiyah dkk, 2018; Sabila dkk, 2018). Fenomena ini menjadi penting untuk diperhatikan mengingat wilayah ini merupakan kawasan padat penduduk dan merupakan jalur penghubung terdekat dari pusat pemerintahan Provinsi Jawa Barat ke wilayah Jawa Barat Selatan (Gambar 2).

Tahapan kegiatan yang dilakukan meliputi:

1. Survei lapangan untuk menghimpun kembali data yang diperlukan dalam menyelesaikan berbagai permasalahan yang timbul di masyarakat.
2. Pendekatan kuantitatif deskriptif digunakan dalam analisis data untuk mengetahui situasi terkini masyarakat Desa Cisewu yang menjadi target kegiatan.

3. Desain kegiatan dan memilih metode yang tepat agar masyarakat merespon dengan baik kegiatan yang diterapkan.

4. Membagi target kegiatan sesuai kondisi masyarakat, misalnya berdasarkan umur, tingkat pendidikan, kegiatan usaha, dsb.

5. Pelaksanaan kegiatan berupa sosialisasi, simulasi dan pendampingan.

6. Dokumentasi kegiatan.

7. Pelaporan dan penyusunan artikel ilmiah serta produk luaran lainnya.

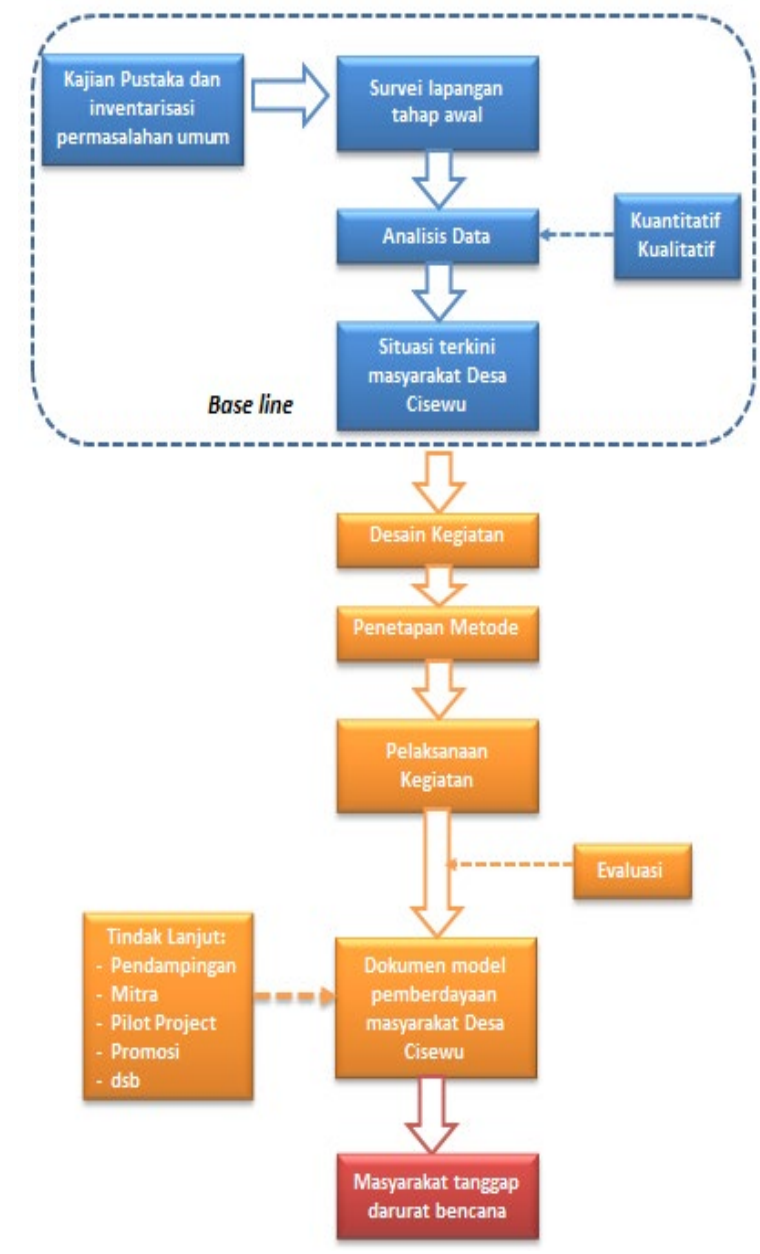

Gambar 2. Kerangka tahapan kegiatan pemberdayaan masyarakat

Kegiatan sosialisasi dapat berupa ceramah dengan bahasa yang mudah dimengerti, dilanjutkan dengan simulasi dan praktek pengenalan fenomena alam yang terkait dengan ancaman logsor. Objek yang terkait dengan fenomena ditunjukkan dan diberikan penjelasan secara terperinci. Kegiatan dapat dilakukan di ruangan sekolah, di balai desa, di tempat usaha maupun di alam. Materi sosialisasi harus terintegrasi dengan aspek budaya lokal. Oleh karena itu dokumentasi budaya masyarakat setempat juga penting. Diharapkan metode ini dapat mempermudah 
Tabel 1. Tahapan kegiatan pemberdayaan masyarakat di Desa Cisewu

\begin{tabular}{|c|c|c|c|c|}
\hline \multirow{2}{*}{ No } & \multirow{2}{*}{ Kegiatan } & \multicolumn{3}{|c|}{ Keterlibatan dalam kegiatan } \\
\hline & & Dosen & Mahasiswa & Masyarakat \\
\hline 1 & Survei lokasi & Melaksanakan survei lapangan & $\begin{array}{l}\text { Mendukung kegiatan survei } \\
\text { bersama dosen }\end{array}$ & $\begin{array}{l}\text { Menjadi sumber informasi terkait } \\
\text { permasalahan di wilayahnya }\end{array}$ \\
\hline 2 & Inventarisasi data & $\begin{array}{l}\text { Mengumpulkan data sekunder dan } \\
\text { primer }\end{array}$ & $\begin{array}{l}\text { Mengumpulkan data } \\
\text { sekunder dan primer }\end{array}$ & $\begin{array}{l}\text { Membantu dosen dan mahasiswa } \\
\text { mendapat akses data yang diperlukan }\end{array}$ \\
\hline 3 & Menyusun Dokumen & $\begin{array}{l}\text { Desain dokumen pemberdayaan } \\
\text { masyarakat }\end{array}$ & $\begin{array}{l}\text { Membantu menyusun } \\
\text { program }\end{array}$ & Membantu melengkapi data \\
\hline 4 & $\begin{array}{l}\text { Sosialisasi dan } \\
\text { pendampingan }\end{array}$ & Melaksanakan program & $\begin{array}{l}\text { Aktif membantu } \\
\text { melaksanakan program }\end{array}$ & Aktif berpartisipasi \\
\hline 5 & Evaluasi & $\begin{array}{l}\text { Memeriksa rencana program dan } \\
\text { realisasinya }\end{array}$ & Membantu evaluasi & $\begin{array}{l}\text { Aktif berpartisipasi memberi } \\
\text { masukan untuk perbaikan }\end{array}$ \\
\hline
\end{tabular}

masyarakat untuk memahaminya. Sehingga akan timbul kesadaran bahwa keselamatan jiwa masyarakat itu sangat penting dan harus diupayakan oleh masyarakat sendiri.

Dalam jangka waktu tertentu setelah pelaksanaan kegiatan dilakukan survei ulang untuk mengetahui perubahan dan dampak positif yang terjadi di masyarakat. Selanjutnya perlu dibina juga perwakilan dari masyarakat setempat agar tetap waspada dan tanggap kapanpun kejadian terkait bencana terjadi. Dengan sendirinya lambat laun akan terbentuk masyarakat yang tanggap akan bencana akibat keterbatasan alamnya. Selain tanggap terhadap bencana longsor, masyarakat di kawasan ini juga harus diberdayakan. Potensi lokal harus didampingi untuk diangkat dan dikenalkan secara lebih luas. Ekonomi masyarakat harus tumbuh untuk meningkatkan kesejahteraan masyarakat Desa Cisewu.

\section{HASIL DAN PEMBAHASAN}

\section{Kawasan Rawan Longsor}

Kecamatan Cisewu terdiri atas 9 desa, yaitu sukajaya, Cikarang, Pamalayan, Cisewu, Girimukti, Nyalindung, Karangsewu, Mekarsewu, dan Panggalih (BPS, 2016). Letak kesembilan desa seluruhnya berada di lereng perbukitan. Lebih dari 50\% wilayah ini memiliki kemiringan lereng $40 \%$ atau lebih (Tabel 2).

Di wilayah Kecamatan Cisewu terdapat 5 sungai yang melintas, yaitu sungai Cihideung, Cilayu, Cilaki, Cikidang dan Cikawung. Sungai Cilaki merupakan sungai terpanjang yang melintasi wilayah Kecamatan Cisewu sepanjang 33 $\mathrm{Km}$. Sungai ini juga mempunyai anak sungai terbanyak yaitu sekitar 16 anak sungai. Sungai Cilaki merupakan batas alam antar Kecamatan Cisewu Kabupaten Garut dan Kecamatan Cidaun Kabupaten Cianjur (Gambar 3a).

Tabel 2. Distribusi kemiringan lereng di wilayah Kecamatan Cisewu (BPS, 2016)

\begin{tabular}{ccc}
\hline No & Kemiringan lereng & Luas (Ha) \\
\hline 1 & $0-2 \%$ & 1.732 \\
2 & $2-5 \%$ & 1.601 \\
3 & $15-40 \%$ & 6.282 \\
4 & $>40 \%$ & 7.668 \\
\hline
\end{tabular}

Kondisi wilayah Kecamatan Cisewu dan sekitarnya secara geologi cukup kompleks, baik kombinasi litologi maupun struktur geologi (Alzwar dkk, 1992; Koesmono dkk, 1996; Gambar 3). Hal ini mengakibatkan sebagian wilayah Kecamatan Cisewu terancam oleh beragam bahaya geologi. Kejadian yang pernah terjadi di wilayah ini adalah gerakan tanah, banjir bandang, dan kegempaan. Lahan pemukiman dan pertanian sebagian mengalami longsor dan bahkan ambles (Gambar 3d). Seperti yang pernah terjadi pada tanggal 16 Desember 2010 sekitar pukul 09.00 WIB, sebuah tebing telah longsor sepanjang 2.500 meter dan lebar 300 meter (Tempo, 2010; dalam Ridwan dkk, 2018). Material longsoran ini menimbun 3 ekor kerbau, 3 hektar sawah dan 2 hektar kebun milik warga sekitar. Selain itu sebanyak 8 rumah milik warga yang dihuni oleh 28 jiwa juga terancam longsor.

Hampir sepanjang jalan Pangalengan - Talegong Cisewu terancam oleh tebing yang longsor (Gambar 3d). Kondisi jalan yang berkelok tajam serta sempit berada di pinggir tebing yang curam menjadikan jalur ini memiliki risiko bahaya yang tinggi. Apalagi bagi wisatawan yang pertama kali melalui jalur tersebut menuju Rancabuaya dan tempat rekreasi lainnya di wilayah pantai selatan. Kondisi ini menjadi ancaman utama bagi penduduk di wilayah Cisewu dan sekitarnya.

\section{Hasil Survei Penduduk dan Jajak Pendapat Mitigasi Bencana}

Penduduk Kecamatan Cisewu 33.770 orang, yang terbanyak terdapat di Desa Cisewu yaitu sebanyak 5.326 orang dengan distribusi berimbang antara lakilaki dan perempuan (BPS, 2016; Tabel 3). Kepadatan penduduk Kecamatan Cisewu sebesar 259 orang/ $\mathrm{km}^{2}$. Desa Cisewu menempati urutan ke-2 dalam hal kepadatan penduduk yaitu 517 orang/ $\mathrm{km}^{2}$, sedangkan urutan pertama ditempati Desa Nyalindung sebesar 779 orang $/ \mathrm{km}^{2}$. Kelompok usia anak-anak dan produktif cukup dominan di wilayah ini dibandingkan kelompok usia lanjut (Gambar 4). Tiga teratas dalam jumlah penduduk untuk kelompok usia produktif (1565 tahun) ditempati oleh Desa Cikarang (3.400 orang), Desa Sukajaya (3.256 orang), dan Desa Cisewu (3.174 orang). Potensi sumber daya manusia ini menjadi modal penting dalam pemberdayaan masyarakat di pedesaan. 

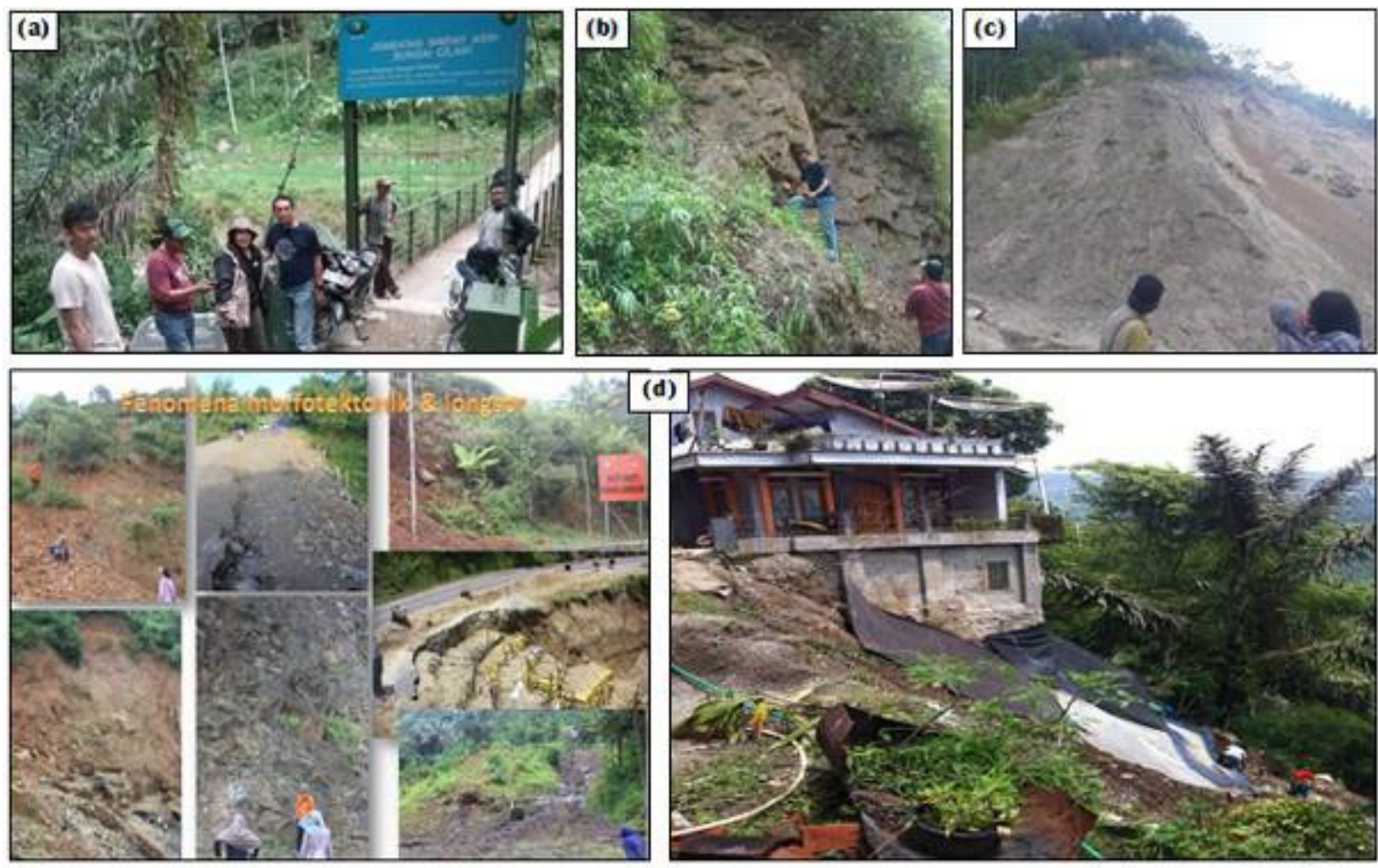

Gambar 3. (a) Jembatan penghubung wilayah Cisewu (Garut) dan Cidaun (Cianjur) membentang di S.Cilaki; (b) Bidang sesar terekam pada intrusi di pinggir jalan Cisewu-Pamalayan-Cidaun di lembah timur hulu DAS Cilaki; (c) Andesit basaltis di jalan Talegong-Cisewu, sebagian teralterasi menjadi kaolin; (d) Fenomena longsor dan ambles di jalur jalan utama Desa Cisewu (Sukiyah dkk, 2018)

Tabel 3. Jumlah penduduk penurut jenis kelamin Kecamatan Cisewu Tahun 2016 (BPS, 2016)

\begin{tabular}{lccc}
\hline \multicolumn{1}{c}{ Desa/Kelurahan } & Laki-laki & Perempuan & Jumlah \\
\hline Sukajaya & 2.580 & 2.543 & 5.123 \\
Cikarang & 2.420 & 2.394 & 4.814 \\
Pamalayan & 1.826 & 1.795 & 3.621 \\
Cisewu & 2.680 & 2.646 & 5.326 \\
Girimukti & 1.896 & 1.945 & 3.841 \\
Nyalindung & 1.790 & 1.794 & 3.584 \\
Karangsewu & 1.005 & 0.997 & 2.002 \\
Mekarsewu & 1.130 & 1.097 & 2.227 \\
Panggalih & 1.636 & 1.596 & 3.232 \\
Jumlah & 16.963 & 16.807 & 33.770 \\
\hline
\end{tabular}

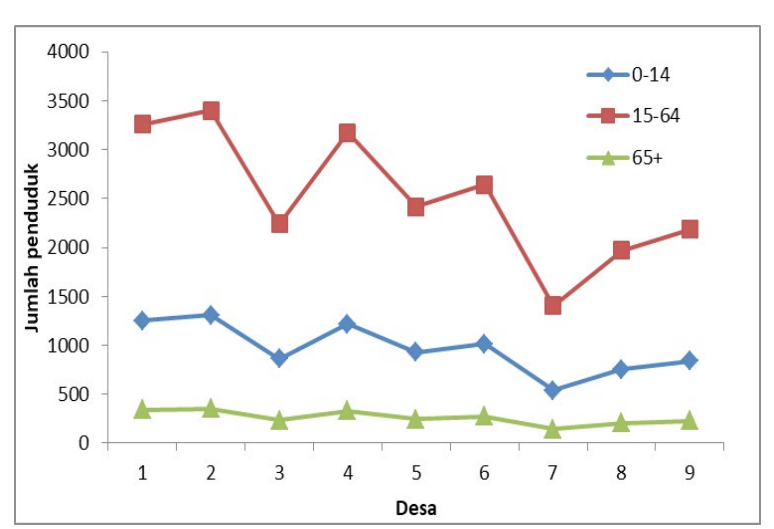

Gambar 4. Grafik distribusi jumlah penduduk menurut kelompok usia (dalam tahun) di wilayah Kecamatan Cisewu Tahun 2016; 1. Sukajaya, 2. Cikarang, 3. Pamalayan, 4. Cisewu, 5. Girimukti, 6. Nyalindung, 7. Karangsewu, 8. Mekarsewu, 9. Panggalih, (BPS, 2016)
Data hasil survei pendapat tentang masalah ancaman bencana longsor di wilayah Desa Cisewu, diperoleh dari hasil kuesioner yang diisi oleh masyarakat sekitar, di antaranya mengenai karakteristik pendidikan, umur dan kerugian akibat bencana longsor. Masyarakat yang mengikuti sosialisasi tanggap bahaya longsor sebanyak 13 orang. Data hasil survei dapat dijelaskan bahwa masyarakat lulusan SLTA/SMA sebanyak 44\%, SLTP/SMP 22\%, Sarjana 22\%, Diploma 6\% dan lainnya $6 \%$. Berdasarkan usia, dari 13 orang yang mengikuti sosialisasi tanggap longsor yang lebih banyak yaitu dari usia 41-55 tahun yaitu 50\%, 21-24 tahun 44\%, dan $>50$ tahun $6 \%$. Masyarakat yang tinggal di Desa Cisewu > 10 tahun sebesar $61 \%,<5$ tahun sebesar $22 \%$ dan $6-10$ tahun sebesar $17 \%$. Berdasarkan karakteristik kerugian masyarakat Desa Cisewu akibat bencana longsor, dapat dijelaskan bahwa:

- Rumah tidak rusak (28\%)

- Rumah rusak namun masih bisa ditempati (44\%)

- Rumah rusak berat dan tidak dapat di tempati (6\%)

- Lahan hilang karena tertimbun / ambles (22\%)

Persepsi masyarakat terhadap pengelolaan bencana diantaranya relokasi pemukiman $(6 \%)$, penanggulangan longsor $(6 \%)$, pengurangan risiko bencana $(6 \%)$, pengurangan bahaya longsor melibatkan masyarakat (82\%). Ketika terjadi longsor, masyarakat Desa Cisewu cenderung melakukan evakuasi (83\%) dan pemindahan penduduk ke lokasi yang lebih aman (17\%). Upaya masyarakat dalam 
mengurangi resiko bencana longsor, diantaranya adalah menutup retakan dengan material lempung $(11 \%)$, tata guna lahan $(56 \%)$, waspada terhadap rembesan air $(0 \%)$, waspada curah hujan yang tinggi (33\%). Masyarakat berharap fasilitas yang perlu dibangun di Desa Cisewu untuk mengurangi resiko bencana longsor diantaranya penghijauan $(61 \%)$, membangun tanggul $(6 \%)$, normalisasi saluran air (22\%), lainnya (11\%). Masyarakat memahami gejala umum tanah longsor di Desa Cisewu meliputi munculnya retakan-retakan di lereng yang sejajar dengan arah tebing (56\%), munculnya mata air baru secara tiba-tiba ( $0 \%$ ), tebing rapuh dan kerikil mulai berjatuhan $(33 \%)$, tidak ada tanda-tanda (11\%). Penyebab bencana longsor di Desa Cisewu menurut masyarakat setempat adalah curah hujan yang tinggi (28\%), beban bangunan $(0 \%)$, penggundulan hutan $(56 \%)$, getaran gempa bumi $(17 \%)$, getaran mesin $(0 \%)$. Perilaku masyarakat pada saat longsor di Desa Cisewu antara lain cemas dengan kondisi rumah (33\%), bingung mengeluarkan barang-barang $(0 \%)$, berdiam diri di rumah ( $0 \%)$, menyelamatkan diri (67\%). Rencana masyarakat berkaitan dengan bencana longsor yang sering terjadi di Desa Cisewu adalah membangun rumah dengan jarak yang jauh dari lokasi longsor (39\%), memperbaiki rumah dan tetap tinggal $(28 \%)$, bertempat tinggal di daerah lain (28\%), tetap tinggal (5\%).

Berdasarkan hasil survei dan jajak pendapat diketahui bahwa masyarakat sebenarnya peduli terhadap kondisi wilayahnya. Mereka ingin dilibatkan dalam proses mitigasi bencana. Masyarakat sudah mengetahui terkait fenomena longsor dan indikasi awal, namun ada hal lain yang penting justru terabaikan. Celah ini yang harus jadi perhatian Pemerintah untuk memberdayakan masyarakat setempat agar lebih peduli terhadap keselamatan jiwa dengan tetap menjaga lingkungannya.

\section{Potensi Lokal}

Berdasarkan data BPS tahun 2016, lahan yang dapat diberdayakan di Desa Cisewu seluas 649 ha, terdiri atas sawah (206 ha), ladang (303 ha), lahan lainnya (140 ha). Hutan lindung pengakuan Desa Cisewu seluas 913,47 ha. Kondisi geomorfologi yang didominasi oleh bentuk lahan perbukitan dan kaki gunung pada umumnya memang lebih sesuai untuk lahan pertanian. Hal ini didukung pula oleh potensi air tanah yang relatif tinggi dan tanah yang subur hasil pelapukan batuan vulkanik yang kaya akan mineral penting bagi tanaman.

Industri kecil atau kerajinan rumahtangga di Desa Cisewu yang tercatat di BPS tahun 2016 berupa kerajinan kulit (4), industri anyaman (9), industri bata (4), makanan (10). Di wilayah Desa Cisewu, jumlah kegiatan usaha sebanyak 31 kegiatan usaha masyarakat, meliputi bengkel mobil/motor (10), reparasi elektronik (6), bengkel las (3), usaha photocopy (5), pangkas rambut (7). Potensi toko terdiri atas Toserba/Minimarket (1), Toko (29), Warung (24). Akomodasi di wilayah ini lebih banyak dibandingkan dengan wilayah desa lainnya, lokasi strategis untuk transit beristirahat sebelum melanjutkan perjalanan untuk berwisata atau beraktivitas di wilayah Jawa Barat selatan lainnya. Akomodasi di Desa Cisewu ini diantaranya hotel 2 dengan kapasitas 14 kamar dan 14 tempat tidur. Rumah makan juga berkembang pesat di Desa Cisewu, diketahui ada 2 rumah makan yang cukup besar dengan 6 karyawan wanita.

Hasil observasi di lapangan berkaitan dengan potensi budaya lokal masyarakat Desa Cisewu berupa aspek kesusastraan yang mencakup ((Irlianti dan Kuraesin, 2018):

- Ungkapan lokal, sejarah dan toponimi, dongeng, rapalan, pantun, ceritra rakyat (folklore);

- Permainan tradisional;

- Kuliner;

- Organisasi sosial;

- Kesenian;

- Kerajinan.

Ungkapan dan perumpamaan yang masih digunakan oleh masyarakat setempat adalah sebagai berikut:

1. Piit-piit ngeundeuk-ngeundeuk buah loa, artinya punya pikiran yang tidak mungkin;

2. Adean ku kuda beureum, hayang pakean tapi meunang nginjeum;

3. Moro julang ngaleupaskeun peusing, ninggalkeun pagawean nu pasti ngungudag pagawean nu can pasti;

4. Ngarep-ngarep kalangkang heulang, ngarep-ngarep nu teu pasti;

5. Kawas cai dina daun taleus, euweuh tapakna;

6. Mobok manggih gorowong, nu rék dituju, geus aya jalan;

7. Ngaletak ciduh sorangan, nu geus dibikeun dicokot deui;

8. Tamiang meulit ka bitis, cilaka ku polah sorangan.

Sejarah lisan berkaitan dengan toponimi Cisewu. Ci adalah Air dan Sewu adalah seribu, jadi menurut warga konon dulu ada mata air seribu. Cisewu dijadikan tempat yang memberikan keberkahan, salah satunya orang yang mau jadi pejabat, mandi di air Cisewu dengan ritual tertentu oleh Kuncen Cisewu yaitu Pak Oong. Asal muasal Kampung Kiara Goong, dulu ada pohon kiara dan ketika malam tiba terdengar suara goong. Tidak diketahui siapa yang membunyikan goong tersebut. Menurut informan Bapa Totong, yaitu sesepuh menurut warga, di Cisewu ada Gunung Gedogan. Di gunung tersebut ada kuda samparani. Ada balong sirah yang sangat ditakuti masyarakat. Melewati balong sirah harus sopan santun, bahkan bahasa juga harus dijaga (Gambar 5a).

Permainan tradisional yang masih dilakukan oleh masyarakat adalah sodlah, gatrik, sapintrong, asepan, kolecer (permainan orang tua), maen kaleci (kelereng), ting-ting kiripit, ucing sumput, paciwit-ciwit lutung, sabintrong, sur-ser, congklak, ngala manuk. Berbagai jenis 
makanan lokal yang terdapat di Desa Cisewu diantaranya adalah gula semut, madu, lompong, humut, trubuk, iwung. Kesenian yang masih berkembang di wilayah Cisewu adalah calung, reog, degung, kecapi suling, karinding, ngagondang, pencak silat, debus, singa depok, lais, ligaswara (kumpulan suara individu). Kerajinan yang terbuat dari bambu dan lidi daun kelapa banyak dikembangkan oleh masyarakat (Gambar 5d). Berbagai produk hasil kerajinan tersebut adalah piring (terbuat dari lidi kelapa), kursi (terbuat dari bambu), tong sampah (terbuat dari bambu), korang (tempat ikan; terbuat dari bambu; bale-bale (terbuat dari bambu), risbang (terbuat dari bambu hitam), angklung (terbuat dari bambu). Organisasi sosial yang ada di Desa Cisewu adalah Ligaswara dan Karangtaruna.

\section{Pemberdayaan Masyarakat}

Berdasarkan analisis data menggunakan pendekatan kuantitatif deskriptif dapat dikemukakan pemberdayaan masyarakat yang dapat dikembangkan di Desa Cisewu, yaitu:

1. Produk lokal dimunculkan dan didampingi.

2. Pembentukan dan pembinaan koperasi.

3. Radio masyarakat ditingkatkan perannya (Sahari dan Anggraini, 2018)

4. Pembinaan kearifan lokal agar lestari (Irlianti dan Kuraesin, 2018)

5. Mitigasi bencana berbasis masyarakat.

Produk lokal yang berpotensi menjadi unggulan Desa Cisewu berupa kuliner dan kerajinan tangan dari bahan yang terdapat di lokasi perlu mendapat pembinaan.
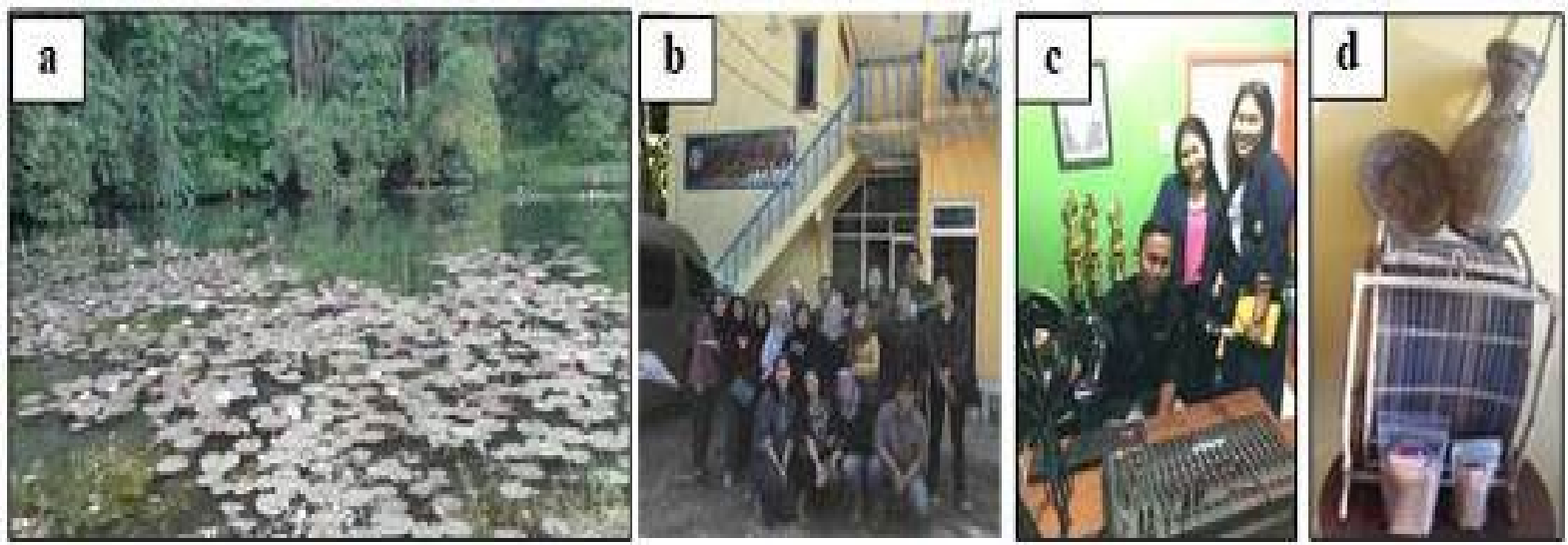

Gambar 5. Sebagian potensi lokal yang terdapat di Desa Cisewu: Kolam Sirah Sewu yang dianggap keramat dengan kuncen Pak Otong (a); Penginapan (b); Studio Rasi FM (c); Gula semut dan kerajinan anyaman lidi dan bambu berupa piring, tong sampah, korang (d).
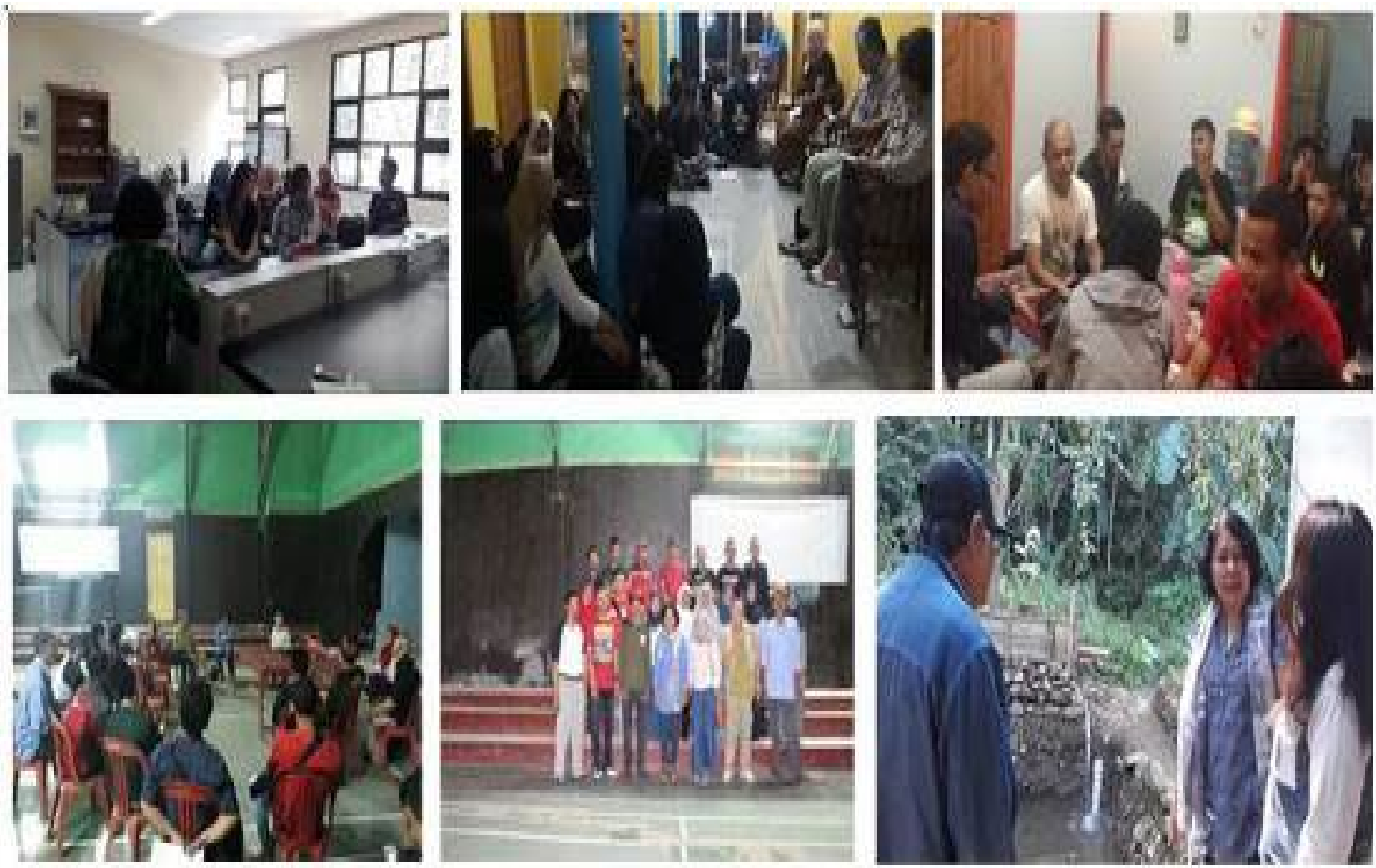

Gambar 6. Diskusi dengan peserta KKN berkaitan dengan potensi lokal dan sosialisasi kepada masyarakat Desa Cisewu terkait dengan permasalahan longsor serta mitigasi bencana 
Diberikan sentuhan agar berbeda dengan daerah lainnya sehingga dapat menjadi unggulan bagi masyarakat di wilayah tersebut. Gula aren semut misalnya, terkendala perijinan, produksi dan pemasaran. Gula aren semut adalah gula yang terbuat dari nira berbentuk serbuk. Gula aren semut "Arensewu" telah diproduksi oleh Kelompok Tani "Paneresan Panglipur" Kampung Kendal Desa Cisewu Kecamatan Cisewu Kabupaten Garut. Berbeda dengan gula aren cetak, gula aren semut berbentuk serbuk. Nira sebagai bahan pembuatan gula semut ini harus memiliki kualitas yang bagus ( $\mathrm{pH} 7$ ), karena ini akan berpengaruh pada proses pengkristalan setelah gula diaduk. Kualitas nira yang kurang bagus, biasanya dijadikan gula cetak. Gula aren semut memiliki keunggulan yaitu rendah kalori, kadar air kurang dari $2 \%$, memiliki aroma dan cita rasa yang khas, serta efektif dalam penggunaan dan penyajiannya. Usaha gula aren semut ini sangat menguntungkan, karena harga jualnya lebih mahal dari pada gula aren cetak. Perbedaannya yaitu mencapai Rp 5.000/kg lebih mahal gula aren semut. Permintaan pasar juga sangat tinggi, sedangkan ketersediaan produk kurang. Gula "arensewu" ini bahannya alami, 100\% dari nira tanpa tambahan bahan apapun dan tanpa pengawet apapun. Sehingga tidak ada batas kadaluarsa selama disimpan dengan baik.

Usaha gula aren semut sudah ditekuni Pak Syarif sejak tahun 2011, namun pada tahun 2013 usaha ini berhenti karena mengalami beberapa kendala, yaitu akses pemasaran yang masih sulit, masyarakat belum begitu mengenal gula aren semut, serta produksi masih terbatas. Awal tahun 2018 Pak Syarif memulai lagi usaha gula aren semut ini karena melihat peluang pasar yang cukup baik. Kelompok Tani "Paneresan Panglipur" terdiri dari 10 orang, merupakan pengrajin gula semut. Diketuai oleh Pak Syarif, juga sebagai distributor produk tersebut. Gula semut dikumpulkan dari anggota kelompok setiap 2-3 hari dengan jumlah $23-25 \mathrm{~kg}$ atau rata-rata setiap anggota menghasilkan 2,3-2,5 kg per dua hari. Produksi gula aren semut merupakan usaha sampingan yang bisa dikerjakan sebelum atau setelah berkebun. Selain dikemas ke dalam zipper bag, produk gula aren semut juga diberi label. Distribusi gula aren semut ke warung, toko, rumah makan, serta losmen-losmen yang berada di daerah Cisewu. Produk"Arensewu" ini belum memiliki hak paten atau izin dari BPOM. Hal ini disebabkan bukan karena produk ini tidak sehat atau tidak layak makan, namun dikhawatirkan membutuhkan biaya yang cukup besar untuk pengurusan izin tersebut. Produk "Arensewu" ini sering dikenalkan dalam beberapa event yang diadakan di luar kota, pemint banyak serta memberi saran agar dipasarkan lebih luas lagi. Namun yang ditakutkan, ketika produk ini dipasarkan lebih luas lagi dan permintaan pasar tinggi, ketersediaan barang kurang dikarenakan produksi masih sedikit. Di daerah Cisewu ini banyak sekali pengrajin gula, namun mereka masih memproduksi gula gandu, enggan memproduksi gula aren semut dengan alasan pembuatan gula semut lebih ribet dan membutuhkan waktu lebih lama. Pengrajin gula aren gandu juga berpikir bahwa pembuatan gula aren semut itu selain ribet dan lama, juga pembuatannya bergantung pada cuaca karena di tahap akhir membutuhkan sinar matahari untuk mengeringkan. Pak Syarif sebagai salah satu motivator pembuatan gula aren semut ini sudah berusaha keras mengajak para pengrajin gula aren gandu untuk membuat gula aren semut, namun tetap saja tidak mendapat respon yang baik. Penyuluhan, sosialisasi bahkan pelatihan pembuatan gula aren semut sudah beberapa kali dilakukan, namun tetap saja tidak banyak yang tertarik untuk bergabung dalam kelompok tani ini.

Beberapa usaha penginapan perlu dibina sehingga dapat membentuk suatu korporasi semacam koperasi yang dikelola oleh masyarakat setempat. Fasilitas penginapan di beberapa lokasi cukup memadai dan tarif terjangkau (Gambar 5). Pengunjung pada umumnya turis atau pedagang yang melalui jalur Cisewu untuk berwisata ke Pantai Rancabuaya dan obyek wisata lain di Jawa Barat Selatan. Pada waktu tertentu disewakan secara khusus bagi karyawan atau tenaga ahli yang bekerja pada Mikrohidro Cilaki yang lokasinya di wilayah Cisewu. Namun sayang, usaha penginapan ini belum dikelola dengan baik, sehingga terkesan seadanya. Padahal jika masyarakat diberdayakan melalui usaha penginapan, potensi ini sangat menjanjikan bagi kesejahteraan masyarakat setempat. Melalui pembinaan dari institusi pendidikan melalui program KKN-PPM diharapkan setahap demi setahap usaha penginapan ini juga menjadi produk unggulan Cisewu, mengingat daerahnya yang strategis sebagai jalur transit. Pemahaman kepada masyarakat terkait keamanan lokasi bangunan penginapan juga harus diberikan sebagai risiko menempati kawasan rawan bencana longsor.

Peran radio masyarakat dapat ditingkatkan, baik sebagai hiburan, pendidikan maupun penyampaian informasi berkaitan dengan mitigasi bencana. RASI FM sebagai radio komunitas di daerah Cisewu mendapatkan kesulitan dana untuk melengkapi peralatan radio (audio console atau mixer dan sound processor) dalam hal optimalisasi kualitas audio untuk produksi iklan layanan masyarakat, jingle, dan bumper (Sahari dan Anggraini, 2018). Peralatan ini akan sangat membantu dalam produksi kebutuhan audio tersebut. Iklan layanan masyarakat, jingle, dan bumper menjadi fokus siaran, sehingga pendengar tidak bosan hanya mendengar suara penyiar saja. Berdasarkan analisis potensi, kegiatan yang bisa dikembangkan oleh RASI FM adalah acara off air. Mereka sering terlibat dalam berbagai event, bahkan berperan sebagai event organizer. Peluang ini bisa melebarkan sayap RASI FM dengan mengadakan acara off air secara rutin, misalnya 4 kali dalam setahun dengan skala acara tingkat desa sampai tingkat kabupaten. Apabila RASI FM bisa mengelola acara rutin secara berkala dengan konsep yang menarik setiap tahunnya, RASI FM akan lebih dikenal lebih luas. Acara off air yang menarik akan mendorong banyak perusahaan untuk bekerja sama 
melalui media partner, berperan untuk mempublikasi acara lewat siaran setiap hari. Untuk mengoptimalkan media partner, RASI FM perlu didorong memiliki akun media sosial Instagram, Twitter, dan LINE@ untuk mempermudah alur komunikasi dan marketing.

Budaya setempat sebagai produk kearifan lokal perlu didata dan didokumentasi. Ide pendirian Galeri Cisewu (GAWU) oleh mahasiswa KKN Unpad perlu direalisasikan (Kuraesin dkk, 2018). Situs Batu Cisewu yang diduga peninggalan Kerajaan Kendan, berupa gunung batu yang diapit S. Cilaki di perbatasan CianjurGarut. Namun, saat ini kawasan Situs terancam hancur akibat penambangan atau pengerukan gunung untuk keperluan lain. Penambangan batu dan pasir membuat sebagian gunung berubah menjadi tebing-tebing setinggi 20 meter yang terlihat seperti sarang semut raksasa, dinding-dinding bukit batu terkikis di setiap sudut. Diduga budaya lokal masyarakat Cisewu merupakan peninggalan kerajaan tersebut. Kemasan kekinian perlu dibantu pengembangannya tanpa meninggalkan substansi. Melalui kearifan lokal ini, pemahaman terkait kebencanaan bisa disosialisasikan. Tanggap terhadap bencana bukan hanya sekedar dipahami tetapi menjadi kebiasaan dalam kehidupan sehari-hari. Sikap reflek dengan sendirinya akan tercipta karena terintegrasi dengan budaya masyarakat setempat.

Mitigasi adalah serangkaian upaya untuk mengurangi risiko bencana, baik melalui pembangunan fisik maupun penyadaran dan peningkatan kemampuan menghadapi ancaman bencana (UU Nomor 24 Tahun 2007 Tentang Penanggulangan Bencana). Masyarakat perlu diberdayakan agar mampu menghadapi ancaman bencana. Sosialisasi kebencanaan harus rutin dilakukan melalui berbagai ajang kegiatan yang melibatkan masyarakat setempat. Sekitar $80 \%$ masyarakat menghendaki keterlibatan secara langsung dalam upaya pengurangan bahaya longsor. Masyarakat beserta budayanya harus dijadikan subyek bukan obyek. Mulai dari usia dini hingga yang sudah lanjut usia. Sikap kewaspadaan harus selalu ditekankan, sehingga ketika bencana terjadi masyarakat sudah siap dan mampu berbuat sesuatu untuk mengurangi risiko yang terjadi. Pepatah masyarakat setempat yang tidak boleh tinggal di suatu kawasan tertentu bisa disinkronkan dengan kondisi lahan yang tidak mungkin dijadikan daerah pemukiman, misalnya karena kemiringan lereng terlalu curam. Undang-Undang nomor 26 tahun 2007 tentang Penataan Ruang perlu memasukkan aspek kearifan lokal agar tidak terjadi penolakan oleh masyarakat yang sudah lebih dulu menempati daerahnya.

\section{SIMPULAN}

Pemahaman masyarakat tentang mitigasi bencana masih rendah dan perlu ditingkatkan, melalui berbagai aspek termasuk melalui bidang-bidang usaha dan kegiatan yang berkembang; Pengelolaan sumber daya kewilayahan di
Desa Cisewu perlu mendapat pendampingan agar muncul inovasi-inovasi yang menjadi unggulan dan sinergi dengan nilai-nilai kearifan lokal; Masyarakat sangat mengharapkan kegiatan pengabdian kepada masyarakat dilaksanakan secara rutin dan berkelanjutan.

\section{UCAPAN TERIMAKASIH}

Terima kasih kami ucapkan kepada pimpinan Universitas Padjadjaran atas dukungan dana PPM Tahun 2018. Kepada Kepala Desa Cisewu beserta jajarannya kami juga mengucapkan terima kasih atas fasilitas dan sambutannya selama pelaksanaan kegiatan PPM dan KKN, serta mahasiswa KKN Unpad tahun 2018 yang telah berpartisipasi dalam kegiatan PPM ini. Semoga artikel ini dapat menjadi sumbangan berarti bagi masyarakat Desa Cisewu.

\section{DAFTAR PUSTAKA}

Alzwar, M., Akbar, N. \& Bachri, S. 1992. Geologi Lembar Garut dan Pameungpeuk, Jawa, Skala 1:100.000. Bandung: Pusat Penelitian dan Pengembangan Geologi.

Badan Pusat Statistik (BPS). 2016. Garut Dalam Angka. (https://garutkab.bps.go.id/index.php/ pencarian? keywordforsearching=CISCIS\&yt1=Cari, diakses 1 November 2017).

Fauzielly, L., Jurnaliah, L, Jihadi, L.H., Aditio, M., Ramadhan, T.H., dan Mufti, I.J. 2018. Sosialisasi mitigasi bencana longsor di Daerah Hambalang, Kecamatan Citeureup, Kabupaten Bogor. Dharmakarya. 7 (1) 11-13.

Fikri, Thoni. 2015. Cara Membuat Gula Semut dari Nira Aren dan Kelapa. (www.masfikr.com, diakses 5 Juli 2018).

Google Map. 2017. Peta lokasi Kecamatan Cisewu. (https:/www.google.co.id/maps/ dir/ Bandung,+Kota+Bandung,+Jawa+Barat/ Cisewu,+Kabupaten+Garut,+Jawa+Barat/, diakses 2 Juni 2017).

Irlianti, I, dan Kuraesin, D. 2018. Budaya Masyarakat Desa Cisewu. Laporan KKNM. Bandung: Universitas Padjadjaran.

Koesmono, K., Kusnama, \& Suwarna, N. 1996. Peta Geologi Lembar Sindangbarang dan Bandarwaru. Skala 1:100.000, Edisi ke-2. Bandung: Pusat Penelitian dan Pengembangan Geologi.

Kuraesin, D., Harnadi, D., Irlianti I., Salsabila, N.E. 2018. GAWU (Galeri Cisewu): Sarana pertunjukan budaya masyarakat Cisewu Kabupaten Garut dalam konservasi dan pengembangan Situs Cisewu sebagai destinasi Geowisata. Proposal 
Program Kreativitas Mahasiswa (bagian dari Laporan KKN-PPM). Bandung: Universitas Padjadjaran.

Kuswandoro, W. E. 2016. Strategi Pemberdayaan Masyarakat Desa Berbasis Partisipasi. (https:// www.researchgate.net/publication/311101048, diakses 21 Desember 2018).

Muhamad, N.R., Maghfirannisa, R., Nabila, M., Lisnawati, A., Nasution, R.A.M., dan Fazrin, A.M. 2018. Survei pengetahuan masyarakat terhadap mitigasi bencana longsor dan gempa bumi di Desa Cisewu Kabupaten Garut. Laporan KKN. Bandung: Universitas Padjadjaran.

Reulina, L., Novelyarisyanti, N., Sayyidi, M. 2011. Tanggap sistem penanggulangan bencana longsor pada daerah Kabupaten Bandung selatam yang berwawasan masyarakat. Program Kreativitas Mahasiswa Bidang Pengabdian Kepada Masyarakat. Makassar: PIMNAS XXIV

Ridwan, P., Damayanti, S., dan Janery, V.N. 2018. Mengetahui arah pergerakan tanah akibat longsor dan gempa bumi di Desa Cisewu Kabupaten Garut. Laporan KKN. Bandung: Universitas Padjadjaran.

Sabila, Z.S., Sukiyah, E., Boy Yoseph CSSSA, Zakaria, Z. 2018. Identifikasi gerakan tanah (longsor) di Kabupaten Garut Jawa Barat. Bulletin Scientific Contribution GEOLOGY, 16 (1) 65-70.

Sahari, G.H., dan Anggraini, A.R. 2018. Mengoptimalkan Radio Komunitas RASIFM Desa Cisewu. Laporan KKNM. Bandung: Universitas Padjadjaran.

Sukiyah, E., Patonah, A, Devnita, R. 2018. Pemberdayaan masyarakat Desa Cisewu Kecamatan Cisewu Kabupaten Garut dalam mewujudkan masyarakat tanggap bahaya gerakan tanah. Laporan Akhir Pengabdian Kepada Masyarakat. Bandung: Universitas Padjadjaran.
Sukiyah, E., Patonah, A., Devnita, R. 2018. Model korelasi zona patahan aktif-gerakan tanah di wilayah Jawa Barat Selatan. Laporan Akhir Tahun ke-2 RKDU. Bandung: DRPMI, Universitas Padjadjaran.

Sukiyah, E., Zakaria, Z., dan Patonah, A. 2017. Model korelasi zona patahan aktif - gerakan tanah di wilayah Jawa Barat Selatan. Laporan Akhir Tahun ke-1 RKDU. Bandung: DRPMI, Universitas Padjadjaran.

Sukiyah, E., Syafri, I., Winarto, J.B., Susilo, M.R.B., Saputra, A., and Nurfadi, E. 2016. Active faults and their implications for regional development at the southern part of West Java, Indonesia. Christchurch: Proceeding the FIG Working Week "Recovery from Disaster".

Sukiyah, E., Syafri, I., Sjafrudin, A., Nurfadli, E., Khaerani, P., Simanjuntak, Dian P.A. 2015. Morphotectonic and satellite imagery analysis for identifying Quaternary fault at Southern part of CianjurGarut region, West Java, Indonesia. Philippine: Proceeding of The 36th Asian Conference on Remote Sensing.

Suwarno, D.N., Andrian, D. 2015. Introduksi pengembangan masyarakat petani melalui pemanfaatan lahan kritis untuk peternakan ruminansia di Desa Jangalaharja dan Dsa Giriharja Kecamatan Rancah Kabupaten Ciamis. Dharmakarya. 4 (2) 83-87.

Undang - Undang Nomor 24 Tahun 2007 Tentang Penanggulangan Bencana

Undang - Undang Nomor 26 tahun 2007 Tentang Penataan Ruang 